\title{
Future Regional Projections of Extreme Temperatures in Europe: A Nonstationary Seasonal Approach
}

\author{
M. D. Frías · R. Mínguez • J. M. Gutiérrez • \\ F. J. Méndez
}

Received: 15 March 2011 / Accepted: 28 October 2011 / Published: 9 June 2012

(Published in Climatic Change, 113: 371-392. doi: 10.1007/s10584-011-0351-y)

Abstract This paper analyzes changes of maximum temperatures in Europe, which are evaluated using two state-of-the-art regional climate models from the EU ENSEMBLES project. Extremes are expressed in terms of return values using a time-dependent generalized extreme value (GEV) model fitted to monthly maxima. Unlike the standard GEV method, this approach allows analyzing return periods at different time scales (monthly, seasonal, annual, etc). The study focuses on the end of the 20th century (1961-2000), used as a calibration/validation period, and assesses the changes projected for the period 2061-2100 considering the A1B emission scenario.

The performance of the regional models is evaluated for each season of the calibration period against the high-resolution gridded E-OBS dataset, showing a similar South-North gradient with larger values over the Mediterranean basin. The inter-RCM changes in the bias pattern with respect to the E-OBS are larger than the bias resulting from a change in the boundary conditions from ERA-40 to ECHAM5 20c3m. The maximum temperature response to increased green house gases, as projected by the A1B scenario, is consistent for both RCMs. Under that scenario, results indicate that the increments for extremes (e.g. 40-year return values) will be two or three times higher than those for the mean seasonal temperatures, particularly during Spring and Summer in Southern Europe.

M. D. Frías

Department of Applied Mathematics and Computer Science. Universidad de Cantabria. Avd. de los Castros s/n, Santander, 39005 Spain.

Tel.: +34 942203948

E-mail: friasmd@unican.es

R. Mínguez

Environmental Hydraulics Institute (IH Cantabria), Universidad de Cantabria. C/ Isabel Torres 15, Santander, 39011 Spain.

J. M. Gutiérrez

Instituto de Física de Cantabria, CSIC-UC. Santander, 39005 Spain.

F. J. Méndez

Environmental Hydraulics Institute (IH Cantabria), Universidad de Cantabria. C/ Isabel Torres 15, Santander, 39011 Spain. 
Keywords extreme temperature · non-stationary GEV · Return values · Europe · Regional Models · ENSEMBLES

\section{Introduction}

Over the last decade, several regions of the world have experienced major floods and heat waves, for instance, the 2003 summer heat wave over Europe (Shär and Jendrithzky, 2004). These extreme events have provoked enormous consequences on society and ecosystems. Besides, there is growing evidence that climate change has the potential to alter the frequency and intensity of extremes, thus driving more severe events with unpredictable consequences (Kharin and Zwiers, 2005; Tebaldi et al, 2006). Therefore, the projection of climate extremes under different future scenarios is a crucial information to assess the potential impacts of climate change on human and natural systems, which are more sensitive to changes related to extreme events than those associated with mean climate conditions (see, e.g. Kunkel et al, 1999).

Nowadays, the main tools available for performing this task are the ensembles of global (Meehl et al, 2007) and regional (Christensen et al, 2007) climate model simulations (referred to as GCMs and RCMs, respectively). These are produced by the international climate modeling community in the framework of different international projects. These models have characteristic resolutions of 250 and $25 \mathrm{~km}$, respectively, and the resulting simulations project the climate according to different emission scenarios for the XXI century. These different simulations provide an estimate of the underlying uncertainty. In particular, the project ENSEMBLES (van der Linden and Mitchell, 2009) is an example of a major international effort to provide, among other things, a coordinated multi-RCM ensemble of regional projections over Europe, considering both an ERA40-forced control period (1960-2000) and A1B scenarios (2001-2100) using forcings from different GCMs. The analysis of this dataset has mainly focused on the mean climate (see the special volume Kjellstrom and Giorgi, 2010) and on particular proxy indicators of extreme behavior (see, e.g. Fischer and Schar, 2010; Herrera et al, 2010, for an study over Europe and over the Iberian peninsula, respectively).

On the other hand, the statistical theory of extreme values (Coles, 2001) provides the mathematical framework for modeling the tail distribution of climate variables, i.e. the extreme values. These models allow us to obtain useful information, such as return period values for certain variables. For instance, the generalized extreme value (GEV) distribution has been used in different climate studies to model block extremes, typically annual maxima or minima, both in observed and simulated data (Kharin et al, 2005; Goubanova and Li, 2007; Kioutsioukis et al, 2010). In particular, the recent study by Nikulin et al (2011) applies the GEV distribution considering annual maxima to one of the ENSEMBLES models described above, forced by several GCMs in future climate conditions. As a result, for instance, they report annual 20-year return values for maximum temperatures related to both control and future scenarios.

Recent advances in extreme value theory allow introducing time-dependent variations in the GEV models. In this kind of approach, parameters are replaced by different functions dependent of time (Coles, 2001). In a simple setting, the parameters can include a trend term varying linearly with time (Cooley, 2009) or a forcing term varying with some external climatic indices, such as the Southern Oscillation Index or the North Atlantic Oscillation (NAO). For instance, Kharin and Zwiers (2005) apply a GEV distribution with parameters, depending linearly on time, to analyze global changes in 
temperature and precipitation from global climate change simulations. There are also studies combining both approaches (Méndez et al, 2007; Brown et al, 2008); for instance, Brown et al (2008) study global changes in extreme daily temperature since 1950 considering the existence of trends and the influence of the NAO. More complex approaches consider harmonic functions reflecting the seasonality of the occurrence of maxima. For instance, Menéndez et al (2009); Izaguirre et al (2010) developed a timedependent model based on the GEV distribution that accounts for the seasonality and interannual variability of extreme wave height. In this case, the non-stationary behavior is parameterized using functions of time (harmonic functions and covariates) for the parameters of the distribution. A similar approach has been considered by Rust et al (2009) to model extreme precipitation in the UK on a seasonal basis.

The purpose of the present study is twofold. First, we introduce a non-stationary seasonal GEV distribution with time-dependent harmonic location, scale and shape parameters fitted to data considering monthly maxima. This method is suitable to reflect the different impact of climate change in extreme temperatures on different seasons. The second is to apply the resulting model to estimate seasonal return period values of maximum temperatures over Europe considering: i) both the reanalysis-driven regional simulations (1961-2000) and ii) future projections (2061-2100) driven by A1B scenario simulations. The former are used to validate the model and to estimate the biases corresponding to regional models, and the later is used to infer the projected return period values in a changing climate. Simulations from the RCMs are compared to the observed natural variability reflected by the E-OBS dataset, which is a stateof-the-art high-resolution daily dataset for Europe (Haylock et al, 2008). This work is done using two regional models from the state-of-the-art ENSEMBLES dataset of regional climate simulations. These two purposes are addressed to increase the current knowledge of temperature extremes over Europe by means of the application of a nonstationary GEV model to high resolution simulations.

The outline of this paper is as follows. Section 2 describes the different kind of maximum temperature data used. The non-stationary model is introduced in section 3 and is applied to observed extreme temperatures in section 4 . The simulated warm temperature extremes for the end of the 20th century are validated against observations in section 5. Changes projected for the period 2061-2100 are also presented in that section. Finally, in section 6, the main findings of the study are summarized.

\section{Observed and model data}

In this paper we analyze the control and transient simulation of two RCMs from the EU funded ENSEMBLES project (http://www.ensembles-eu.org), which aimed at the generation of climate change scenarios over Europe. ENSEMBLES studied regional climate change from different perspectives and includes a large variety of communities and state-of-the-art methodologies and techniques. In particular, dynamical downscaling of GCM simulations, both control and transient, are performed using nine different RCMs run by different institutions. They cover the entire continental European region with a common resolution of $25 \mathrm{~km}$; some of the models were also run at a $50 \mathrm{~km}$ resolution in order to explore the resolution effect (as far as we know, no result on this issue has been reported yet). More information on the experiments performed can be found in van der Linden and Mitchell (2009). In particular, in this paper we consider the following experiments run in the framework of this project: i) All RCMs driven by re-analysis 
data from the European Centre for Medium Range Weather Forecasts (ECMWF) as boundary conditions (see Uppala and others (2005) for more details about the ERA40 reanalysis); ii) the RCMs driven by control climate scenario $(20 \mathrm{c} 3 \mathrm{~m})$ simulations from different GCMs, and iii) the RCMs also driven by future (A1B scenario) simulations from the same GCMs. The analysis of these experiments allows us estimating different sources of errors and biases in the projections, i.e. data from i) allow to estimate the RCM bias in perfect boundary conditions (optimal conditions), and comparing ii) and i), we can estimate whether the bias pattern is robust in sub-optimal conditions (GCM simulations). If this is the case, then we can apply the standard "delta method" and compute the projected RCM anomaly as the difference of the future and control projections (this difference would remove the RCM bias out of the regional change signal, and would allow to extrapolate the robustness of the bias pattern, obtained in suboptimal conditions, to changing conditions).

Regarding the extreme values, we consider monthly maximum temperature data from the Koninklijk Nederlands Meteorologisch Instituut (KNMI) and the Swedish Meteorological and Hydrological Institute (SMHI). The selection of these RCMs is based on two criteria: i) the period simulated for these models, using the ERA40 reanalysis as boundary conditions, is longer than for other RCMs, and ii) the above two RCMs were forced with driving conditions from the same global model and, thus, conclusions should be attributed to the regional model behavior, not to differences with the GCM considered. Particularly, the two regional models were run using the ECHAM5 GCM for a common control period from 1961 to 2100. In this study, the period analyzed for the future projections extends from 2061 to 2100 . The study by Kjellstrom and Giorgi (2010) shows, for different variables during the control period, an evaluation of the regional climate models from the ENSEMBLES project with respect to the E-OBS dataset. In particular, results for summer maximum temperature reveal a better performance of the KNMI model with respect to the multimodel ensemble (see figures 4 and 5 by Kjellstrom and Giorgi (2010) for more details).

For the purposes of validation of the RCM simulations in present climate, monthly maximum temperature data from the E-OBS grid are considered from 1961 to 2000. The E-OBS dataset is a high-resolution gridded dataset developed in ENSEMBLES for maximum temperature, among other surface variables, and it is provided at both 50 and $25 \mathrm{~km}$ original resolution. This dataset improves previous gridded data over Europe in the number of stations used, being the best publicly available gridded product for Europe to date. However, since station coverage is not homogeneous in space due to data availability/sharing limitations, some problems of lack of representativeness have been pointed out, particularly for extremes (see, e.g. Hofstra et al, 2010; Herrera et al, 2010). Therefore, in this work we consider the observation grid and RCM simulations with the lower $50 \mathrm{~km}$ resolution. This choice is also convenient from a computational point of view, since the parameters of the seasonal GEV model should be optimized at a grid box level (note that the $50 \mathrm{~km}$ grid contains a total of 6271 land grid boxes over Europe). See Haylock et al (2008) for more details about the characteristics of E-OBS dataset and the methodology applied.

\section{Nonstationary Seasonal GEV model}

A GEV model with time-varying location $\left(\mu_{t}\right)$, scale $\left(\psi_{t}\right)$, and shape $\left(\xi_{t}\right)$ parameters is called a nonstationary GEV model (Coles, 2001) and is given by the following 
cumulative distribution function $(\mathrm{CDF})$ :

$$
G\left(x_{t} ; \mu_{t}, \psi_{t}, \xi_{t}\right)=\left\{\begin{array}{l}
\exp \left\{-\left[1+\xi_{t}\left(\frac{x_{t}-\mu_{t}}{\psi_{t}}\right)\right]_{+}^{-\frac{1}{\xi_{t}}}\right\} ; \xi_{t} \neq 0, \\
\exp \left\{-\exp \left[-\left(\frac{x_{t}-\mu_{t}}{\psi_{t}}\right)\right]\right\} ; \xi_{t}=0,
\end{array}\right.
$$

where $[a]_{+}=\max (0, a)$.

The GEV family includes three distributions corresponding to the different types of tail behavior: Gumbel $\left(\xi_{t}=0\right)$ with a light tail decaying exponentially; Fréchet distribution $\left(\xi_{t}>0\right)$ with a heavy tail decaying polinomially, and Weibull $\left(\xi_{t}<0\right)$ with a bounded tail. The corresponding time dependent quantiles $x_{q, t}$ are:

$$
x_{q, t}= \begin{cases}\mu_{t}-\frac{\psi_{t}}{\xi_{t}}\left[1-(-\log q)^{-\xi_{t}}\right], & \text { if } \xi_{t} \neq 0, \\ \mu_{t}-\psi_{t} \log (-\log q), & \text { if } \xi_{t}=0,\end{cases}
$$

where $q$ is the corresponding probability.

In addition to "instantaneous" time dependent quantiles as given in (2), it is of great interest when dealing with maxima the calculation of "aggregated" time dependent quantiles, which would allow us the calculation of different annual return levels $\bar{x}_{q}$ associated with periods equal to or longer than one month $\left(t_{a}, t_{b}\right)$. These return levels correspond to annual probabilities of obtaining a given maximum temperature at any time within the selected time interval. Thus, assuming that $\left(t_{a}, t_{b}\right)$ is given in annual scale, i.e. the period of time between $t_{a}=0$ and $t_{b}=1 / 12$ corresponds to January, the annual return levels $\bar{x}_{q}$ can be obtained solving the following implicit equation:

$$
q=\exp \left\{-k_{m} \int_{t_{a}}^{t_{b}} f\left(\bar{x}_{q}, t\right) d t\right\},
$$

where $k_{m}=12 y^{-1}$ and the function $f\left(\bar{x}_{q}, t\right)$ is equal to:

$$
f\left(\bar{x}_{q}, t\right)= \begin{cases}{\left[1+\xi_{t}\left(\frac{\bar{x}_{q}-\mu_{t}}{\psi_{t}}\right)\right]^{-1 / \xi_{t}}} & ; \text { if } \xi_{t} \neq 0 \\ \exp \left[-\left(\frac{\bar{x}_{q}-\mu_{t}}{\psi_{t}}\right)\right] ; & \text { if } \xi_{t}=0 .\end{cases}
$$

Details about this derivation can be found in Appendix and Menéndez et al (2009).

In this paper, expression (3) is used to calculate annual return levels related to: the whole year, spring, summer, autumn and winter, respectively. The advantage of the proposed formulation is that there is no need to treat data and fitting separately for each period, reducing the uncertainty in the estimation of seasonal and annual return values.

The proposed model and expression (3) for aggregated quantiles rely on the assumption of independency of monthly maxima. To ensure that this condition holds for monthly maximum data, the selection is performed considering a minimum distance between maxima. For this particular case, we have selected 3 days. 
3.1 Model Formulation

Several nonstationary models have been recently introduced to deal with trends and interannual oscillations (see, for instance, Mínguez et al (2010b)). In this study, we consider a non-stationary model for seasonal variations introduced in Menéndez et al (2009), hence dealing with the intra-annual (seasonal) variations of temperature maxima. Within this approach, monthly maximum temperatures $x_{t}$ of successive months are assumed to be independent random variables following a GEV distribution with time-dependent parameters as in (1). To introduce seasonality, the model proposed in Menéndez et al (2009) is stated as follows:

$$
\begin{aligned}
\mu_{t} & =\beta_{0}+\sum_{i=1}^{P_{\mu}}\left[\beta_{2 i-1} \cos (i w t)+\beta_{2 i} \sin (i w t)\right] \\
\log \left(\psi_{t}\right) & =\alpha_{0}+\sum_{i=1}^{P_{\psi}}\left[\alpha_{2 i-1} \cos (i w t)+\alpha_{2 i} \sin (i w t)\right] \\
\xi_{t} & =\gamma_{0}+\sum_{i=1}^{P_{\xi}}\left[\gamma_{2 i-1} \cos (i w t)+\gamma_{2 i} \sin (i w t)\right],
\end{aligned}
$$

where $t$ is given in years, $\log \left(\psi_{t}\right)$ ensures positiveness of the scale parameter $\left(\psi_{t}>\right.$ $0), \beta_{0}, \alpha_{0}$, and $\gamma_{0}$ are mean values, $\beta_{i}, \alpha_{i}$, and $\gamma_{i}$ are the amplitudes of harmonics considered in the model, $w=2 \pi / T$ is the angular frequency, $T$ is one year, and $P_{\mu}$, $P_{\psi}$ and $P_{\xi}$ are the number of sinusoidal harmonics to be considered within the year, associated with the location, scale and shape parameters, respectively. The resulting parameters are estimated using the method of maximum likelihood, where the loglikelihood function is defined as follows:

$$
\begin{aligned}
\ell(\boldsymbol{\theta} ; \boldsymbol{x}, \boldsymbol{t}, \boldsymbol{c}) & =\sum_{t=1}^{n_{d}} \log \left(g\left(x_{t} ; \mu_{t}, \psi_{t}, \xi_{t}\right)\right) \\
& =-\sum_{t=1}^{n_{d}}\left\{\begin{array}{l}
\log \psi_{t}+\left(1+\frac{1}{\xi_{t}}\right) \log z_{t}+z_{t}^{n}, \quad \text { if } \xi_{t} \neq 0, \\
\log \psi_{t}+\frac{x_{t}-\mu_{t}}{\psi_{t}}+\exp \left(-\frac{x_{t}-\mu_{t}}{\psi_{t}}\right), \text { if } \xi_{t}=0,
\end{array}\right.
\end{aligned}
$$

where $\boldsymbol{x}=\left(x_{1}, x_{2}, \ldots, x_{n_{d}}\right)^{T}$ is the sample vector, $n_{d}$ is the number of monthly maxima observations, $z_{t}=1+\xi_{t}\left(\frac{x_{t}-\mu_{t}}{\psi_{t}}\right)$ and $z_{t}^{n}=z_{t}^{-1 / \xi_{t}}$ are auxiliary variables to simplify the computational implementation, and $g\left(x_{t} ; \mu_{t}, \psi_{t}, \xi_{t}\right)=\frac{d G\left(x ; \mu_{t}, \psi_{t}, \xi_{t}\right)}{d x}$ is the GEV probability density function (PDF).

Although sophisticated methods have been proposed for the automatic selection of harmonics (e.g. Mínguez et al, 2010a, present a method based on Akaike information criterion), they would require a prohibitive computational time to be applied to the whole European domain considered in this paper, with 6271 grid points. For this reason, we select the following fixed parameterization for all cases (grid points):

$$
P_{\mu}=3, P_{\psi}=3 \text {, and } P_{\xi}=1 .
$$

To make this decision we use results of different parameterizations for a reduced number of locations or cities (Athens, Brussels, Copenhagen, Lisbon, London, Madrid, 
Oslo, Paris, Rome, Stockholm) using the E-OBS dataset (1961-2000). The reason to take this final parameterization is threefold: i) it is the most complex model with all the parameters being statistically significant on a $10 \%$ level for the test cases performed, ii) we get very good diagnostics for all cases, and iii) it is flexible enough to capture the possible spatial variations over the grid.

The harmonic in the shape parameter $\xi$ was introduced to check whether the tail behavior changes with season. Results are given in Figure 1, where the intra-annual evolution of the shape parameter is shown for each city. Note that the parameters allow the model to fit the particular tail behavior for each location. This figure shows that the tail behavior is Weibull $(\xi<0)$ for all cities (bounded tail behavior). Note that the shape parameter is statistically significant $(90 \%$ confidence intervals does not contain the zero), with a clear seasonality effect, excluding in Paris where a constant shape parameter could be used instead. Since we aim at a common model for all grid points we decided to use the model with an harmonic in the shape parameter, although we are aware that shape parameter may be difficult to estimate due to lack of information in the tails.

Figure 2 shows the seasonal evolution of the fitted location parameter $\mu_{t}$ (solid lines) and $95 \%$ "instantaneous" time dependent percentile $x_{0.95, t}$ (dashed line) for all cities, capturing the seasonal variations. These percentiles are calculated using expression (2). Note that both location and $95 \%$ percentile are conditional on the time of occurrence within the year. Shading indicates $90 \%$ confidence intervals.

Note that abscissas axis in Figures 1 and 2 are presented in annual scale. However, in the upper part of both figures, the correspondence with the different months is also given.

An important issue about the selected model is the decision about not to include parameters accounting for possible trends. One of the aims of the paper is to make a comparison between the fitting using two different periods (1961-2000 and 2061-2100), in order to check i) how the regional climate models perform with respect to maxima observations, and ii) their suitability to be used for the estimation of return levels in the future. For this reason, we decided to fit results from models during those periods independently and without including trends. This strategy allow us to get unique return level values for each period and make a fair comparison. Nevertheless, we are aware of the possibility of including trends in the model, which is a subject for further research.

\subsection{Diagnostics}

Different diagnostic statistics and plots are computed to assess the goodness of fit with respect to the resulting models in the selected cities. In particular, we compute quantile-quantile (Q-Q, see Figure 3) and probability-probability (P-P, not shown due to space limitations) plots, obtaining very good diagnostics, with points close to the diagonal. Note that P-P and Q-Q plots for the sample of computed values $\bar{z}_{t}$ can be obtained as $\bar{z}_{t}=\frac{1}{\xi_{t}} \log \left[1+\xi_{t}\left(\frac{x_{t}-\mu_{t}}{\psi_{t}}\right)\right]$, so that if $\bar{z}_{(1)}, \bar{z}_{(2)}, \ldots, \bar{z}_{\left(n_{d}\right)}$ are the corresponding sample order statistics, the plotting points for the probability plot are $\left\{i /\left(n_{d}+1\right), \exp \left(-\exp \left(-\bar{z}_{(i)}\right)\right)\right\}$ whilst the plotting points for the quantile plot are $\left\{-\log \left(-\log \left(i /\left(n_{d}+1\right)\right)\right), \bar{z}_{(i)}\right\}$. Solid lines in Figure 3 indicate $90 \%$ confidence intervals.

Using the resulting models, we have also calculated annual and seasonal aggregated return levels (3) for the test cities, which provide the knowledge about the mean number of years, springs, summers, autumns and winters, respectively, in which a given 


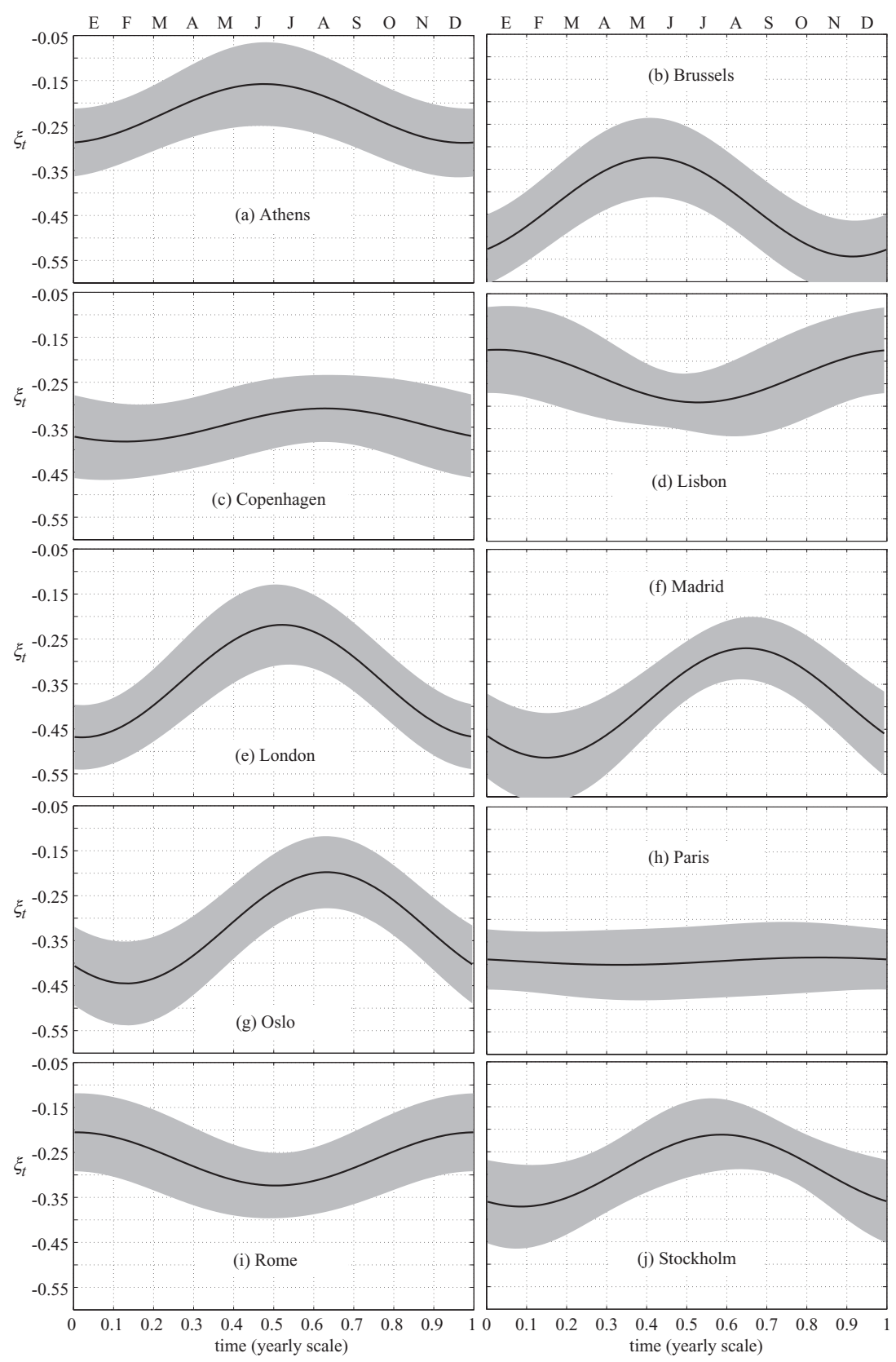

Fig. 1 Goodness of fit plots for the maximum monthly temperature shape parameter, related to the EOBS database, at the selected locations. Shading indicates $90 \%$ confidence intervals.

threshold is exceeded. Note that this information is obtained using only one fitted model for each location. In addition, and in order to compare the robustness of the results, we also compute the annual return level plots using the traditional stationary 


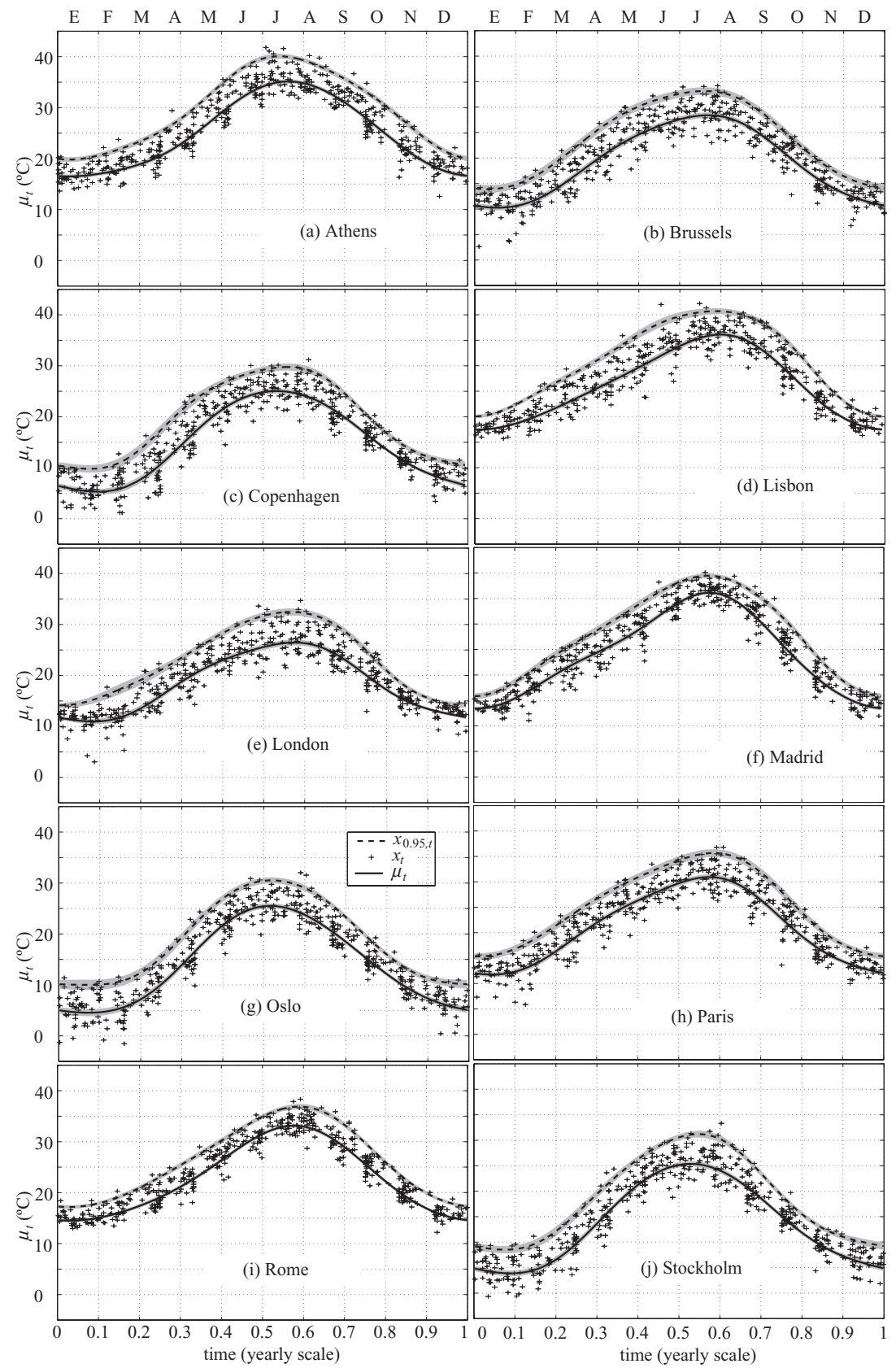

Fig. 2 Goodness of fit plots for the maximum monthly temperature location parameter (continuous line) and 0.95 time dependent quantile $\left(x_{0.95, t}\right.$, dashed line) for the selected locations (in different panels). Shading indicates $90 \%$ confidence intervals.

approach, where only yearly maximum data values are considered. In this regard, the following information is shown in Figure 4: 

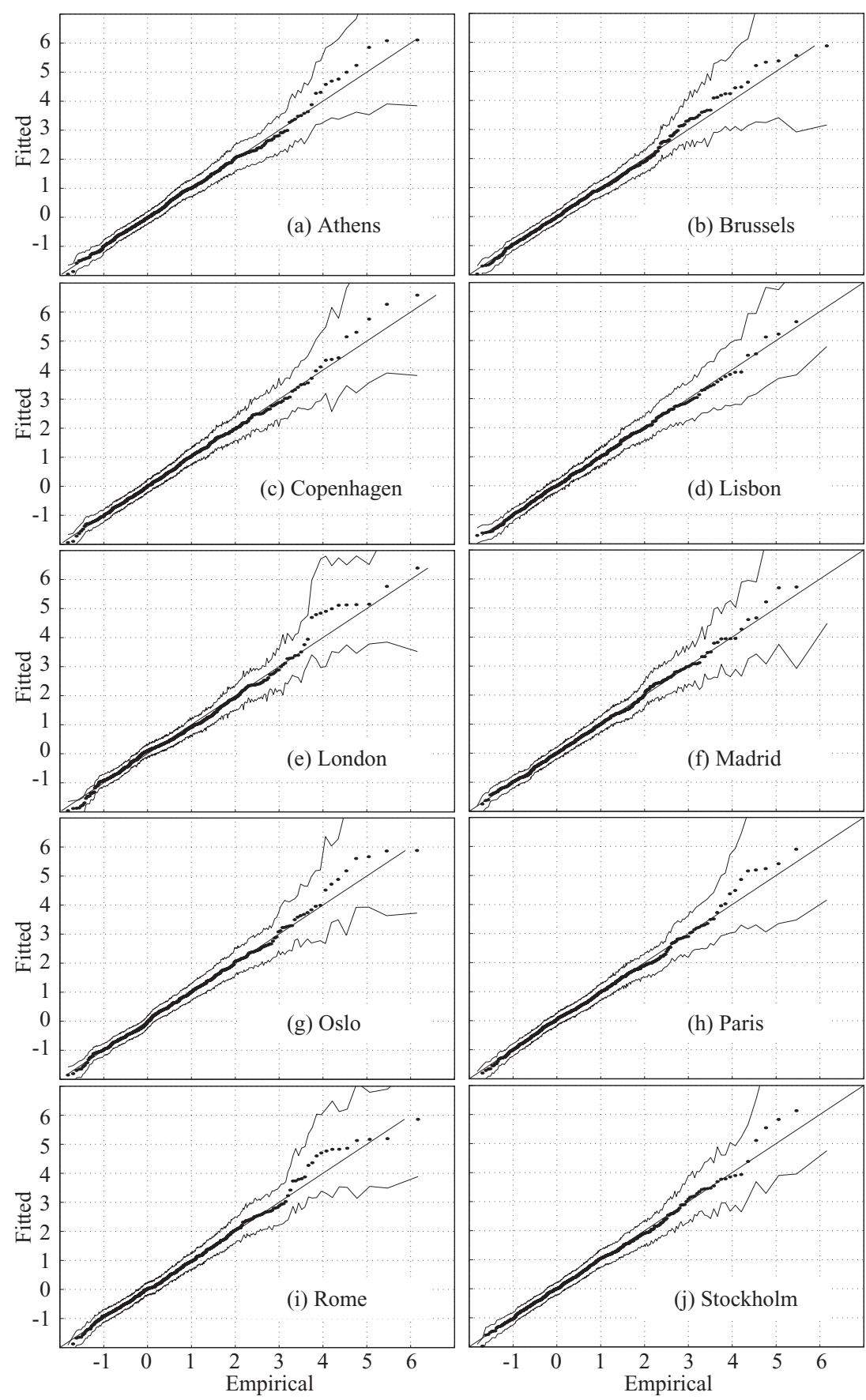

Fig. 3 Goodness of fit Q-Q plots for the selected cities. Solid lines indicate $90 \%$ confidence intervals. 
- Fitted annual return levels (red line) obtained using the non-stationary approach, and $90 \%$ confidence bands (grey shading). Empirical annual return period quantiles (red dots) are also shown, where only the maximum value for each year is used. Note that these points are plotted using the following procedure (Morton et al, 1997): i) ordering the annual maximum values increasingly, ii) assigning to each annual maximum temperature the following empirical probability of occurrence $F_{i}^{\mathrm{AM}}=\frac{i}{n+1}$, where $i$ corresponds to the order in the sample, and iii) calculating the return period as $T_{i}^{\mathrm{AM}}=\frac{1}{1-F_{i}^{\mathrm{AM}}}$.

- Fitted and empirical return levels for: i) spring (green line and dots, respectively), ii) summer (blue line and dots, respectively), iii) autumn (black line and dots, respectively), and iv) winter (gray line and dots, respectively). All of them obtained using the non-stationary model. Note that, analogously to the annual maxima, empirical points have been calculated considering maximum values for each spring, summer, autumn and winter, respectively.

- To check model performance, we have also plotted return levels from the traditional stationary GEV based on annual block maxima (black dot-dashed line).

The above figures provide some interesting information. Since the annual maxima occurs during the summer, annual aggregated quantiles coincide with summer aggregated quantiles for all cities. This result shows the consistency and coherency of the proposed model. Note that blue lines associated with summer are hidden behind annual red lines. The goodness of fit of the selected model is also justified through the comparison with the results using the stationary approach based on annual maxima. Results from this model are plotted using black dot-dashed lines. Note that in all cases, this line is almost indistinguishable with respect to results from the non-stationary approach. This confirms the validity, consistency and coherency of i) the proposed model and ii) the independence assumption between maxima.

Over Europe, the minimum maximum temperatures are always obtained during winter. Note that gray lines related to winter are below the rest of the seasonal quantiles. Autumn presents different maximum temperatures with respect to spring: higher for Athens, Lisbon, London, Madrid, Paris and Rome, and lower for Copenhagen, Oslo and Stockholm. This clearly indicates that springs present higher maximum temperatures than autumns in the South-East part of Europe and United Kingdom, whereas in the North-West part autumns present higher maximum temperatures than springs. For this particular case, Brussels is in the frontier where autumns and springs have similar maximum temperature behavior.

\section{Results for Observed Extreme Temperatures}

In this section, we apply the seasonal GEV model introduced in Sec. 3.1 (calibrated and diagnosed considering ten illustrative locations) to obtain maps of return period values for the whole European domain. To this aim, we consider the E-OBS maximum temperature daily data series in each of the 6271 resulting grid points for the 40 -year period 1961-2000, and focus on return periods for 40 and 100 years; note that $T=40$ establishes the limit of the empirical available data, whereas $T=100$ is far beyond the available data and fully relies in the extrapolation of the tail estimation. Note also that, in this study, the value for a return period $T$ on a particular "season" is the extreme temperature value that is expected to be exceeded on average once every $\mathrm{T}$ years in 
that particular "season". Figure 5 presents a map of 40-year return levels for Spring to Winter over Europe. This figure shows a South-North gradient with larger return levels in the South, especially over the Mediterranean, and lower values in the North. In summer there are less differences between North and South and almost the whole continent shows 40-year return period values in the range from 30 to $40^{\circ} \mathrm{C}$. The same dominant pattern is obtained for return period values associated with other return periods analyzed (20 and 100 years, not shown).

Figure 6 shows the differences of the 100-year return period values relative to those obtained for a 40-year period. Higher values are found for the 100-year return levels for all seasons, although the increments are not high (the maximum increments achieved are around $2^{\circ} \mathrm{C}$ ). This is consistent with the bounded behavior of the tail distribution. In Spring and Autumn the differences are larger in the North-East whereas the maximum during Winter is mostly reached in regions over Central Europe. Differences are more homogeneous over the whole Europe in Summer due to the less strong meridional gradient of the return period values during this season.

\section{Results for RCM Simulated Extreme Temperatures}

Once extremes from the E-OBS pseudo-observations have been analyzed, we focus on the results for the two RCMs considered in this work: KNMI and SMHI.

\subsection{Extremes in a control period}

Firstly, we analyze the simulations performed for the control period 1961-2000, driven by both ERA40 (optimal conditions) and ECHAM5 20c3m scenario (sub-optimal conditions). The comparison of these results with those obtained for the observations in the previous section provides a validation of the RCMs, which allows identifying and removing systematic biases. The main goal is determining whether each RCM has a characteristic regional bias pattern which can be identified out of the global bias of the driving global model (ERA40 or ECHAM5) used as boundary conditions.

Maps for the 40-year return levels obtained for the KNMI and SMHI RCMs (both with ERA40 and ECHAM5 forcings) show a spatiotemporal pattern of return period values similar as that obtained for the observed E-OBS dataset (not shown). A gradient of higher values in the South and lower values in the North is also found for the RCM simulations, attaining also higher values during Summer and lower during Winter. In order to quantify the degree of spatial agreement for the different return value patterns, we compute the Pearson's correlation between E-OBS and each RCM-GCM couple (e.g. KNMI forced by ERA40); the resulting values are shown in the diagram in Fig. 7, next to the arrow linking E-OBS with each of the RCMs. Values significant at $95 \%$ confidence level are plotted in black. The statistical significance has been computed taken into account the spatial autocorrelation by adjusting the effective number of spatial degrees of freedom obtained from the original fields of temperature (see Bretherton et al (1999), and references therein). Note that in all the cases the correlations are over 0.80 indicating a good spatial agreement related to return period values. In order to further explore the differences between the RCMs and the observations, Figure 8 shows the maps of biases between the RCM and the E-OBS values for each season (by 


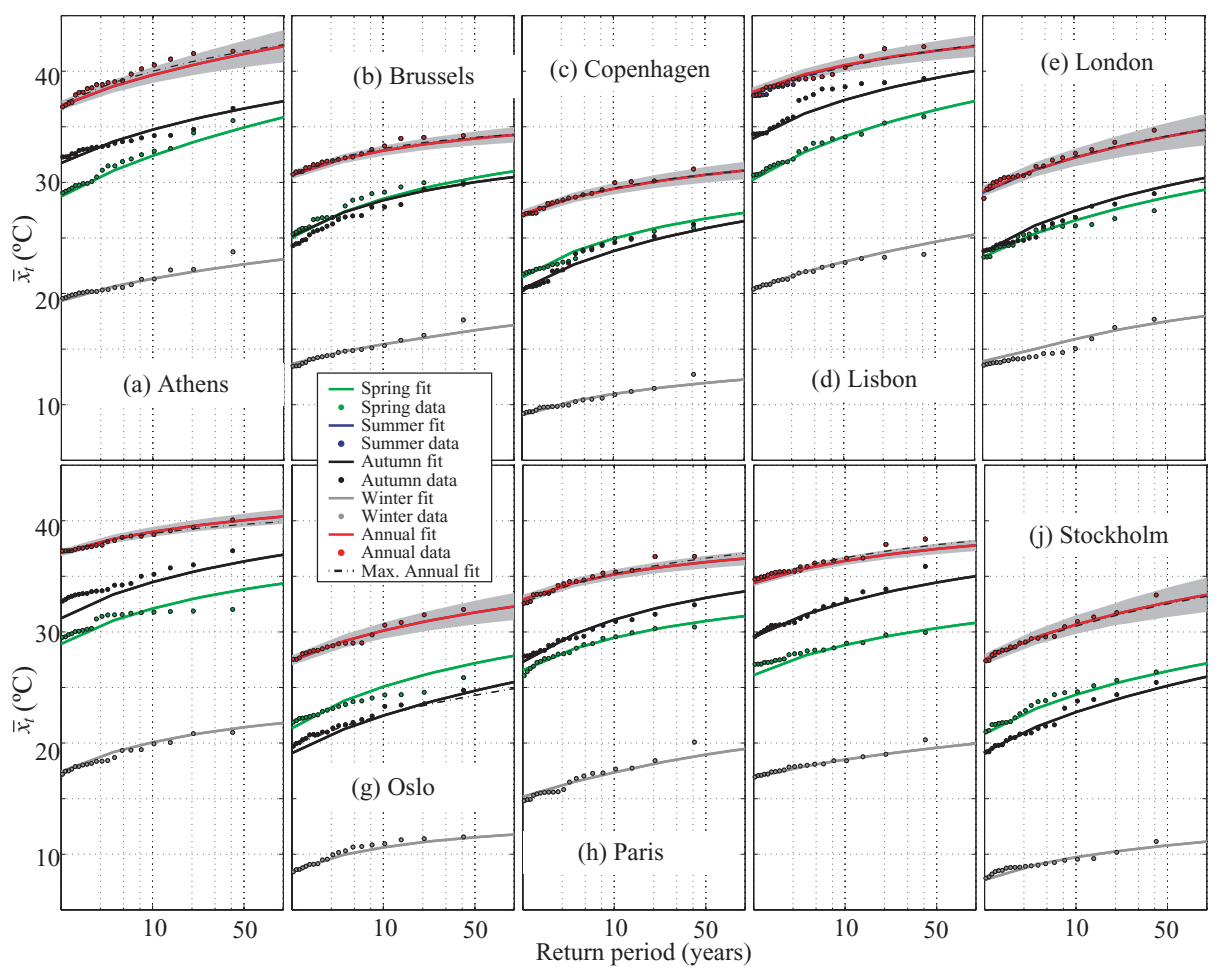

Fig. 4 Return level plots for the selected locations: summer, autumn, winter, spring, and annual using the non-stationary approach, and annual using annual maxima data. Red dashed lines indicate $90 \%$ confidence intervals for the annual quantile.

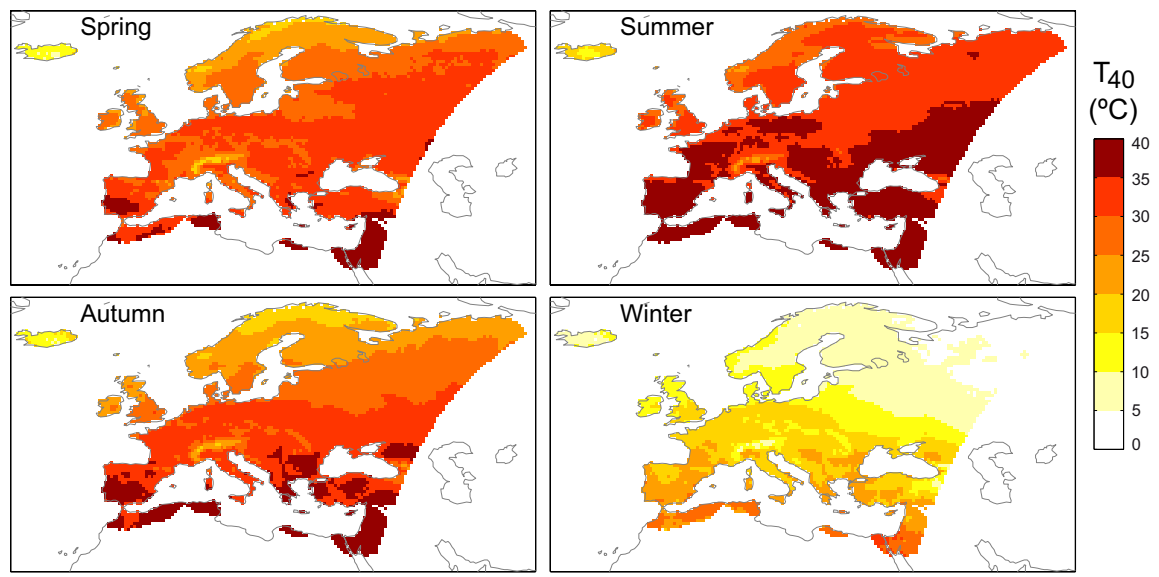

Fig. 5 40-year return period values $\left(T_{40}\right)$ of daily maximum temperature from the E-OBS dataset. The panels show the four seasons. 


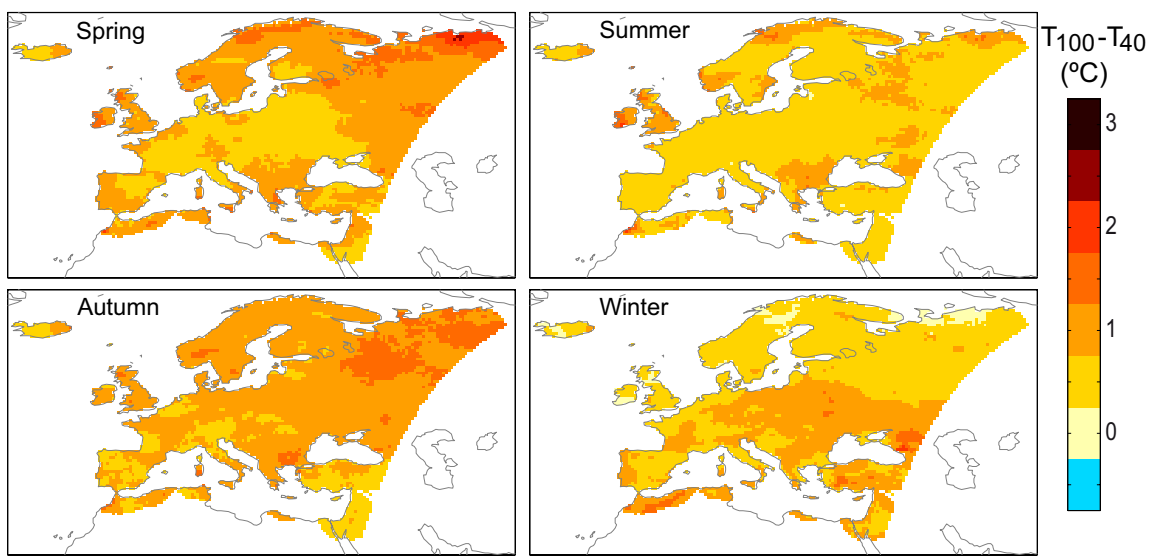

Fig. 6 Changes of 100-year return levels $\left(T_{100}\right)$ relative to 40 -year return levels $\left(T_{40}\right)$ for daily maximum temperature from the E-OBS dataset.

rows) and RCM-GCM couple (by columns). Both KNMI and SMHI present a similar North-South gradient in the bias pattern, with return period values overestimated over Southern Europe and underestimated in the North during Spring, Summer and Autumn. This gradient is more pronounced for the SMHI model, which registers lower values over a larger region with stronger negative differences in the North (around $-5^{\circ} \mathrm{C}$ ). In Winter, both models show a more uniform pattern with smaller bias, especially for the KNMI model. A similar North-South gradient has been found by Nikulin et al (2011) for 20-yr return period values of annual maximum temperature (summer in our study) applying a stationary GEV model to EOBS data and regional simulations from the RCA model forced by 6 GCMs. They also found a higher underestimation over Scandinavia, which seems to be related to the fact that the stations considered in EOBS only represent the open-land temperature, ignoring the forest influence in the maximum daytime temperature. This aspect is particularly important in regions like this, with large forest fractions.

An important result is that KNMI and SMHI models exhibit the same characteristic regional bias pattern (with small differences) for the two different global forcing conditions (reanalysis from ERA40 or control simulations from ECHAM5), so the inter-RCM variability of the bias pattern is much higher than the inter-GCM variability in the resulting patterns. In order to quantify the degree of spatial agreement for the different patterns, we compute the Pearson's correlation for the bias patterns (w.r.t. E-OBS) for each RCM-GCM couple; the resulting values are shown within the dashed box in the diagram in Fig. 7. As explained above, correlations in black are significant at $95 \%$ confidence level taking into account the spatial autocorrelation. For instance, in Spring (labelled as "P" in the diagram), the intra-RCM (for ERA40 and ECHAM5 forcings) correlations are 0.89 for both the KNMI and SMHI models, whereas the inter-RCM (intra-GCM) correlations are 0.70 and 0.82 , respectively. Note that the correlations between the global (ERA40 and ECHAM5) and regional (KNMI and SMHI) biases are much lower being in some cases not significant $(0.37,0.31,0.37$ and 0.42 , for the respective combinations, also shown in the diagram in Fig. 7), thus indicating a robust regional pattern in the bias of the RCMs with respect to the observations. As expected, lower correlations were obtained between the ERA-40 bias and the ECHAM5 bias (0.38 


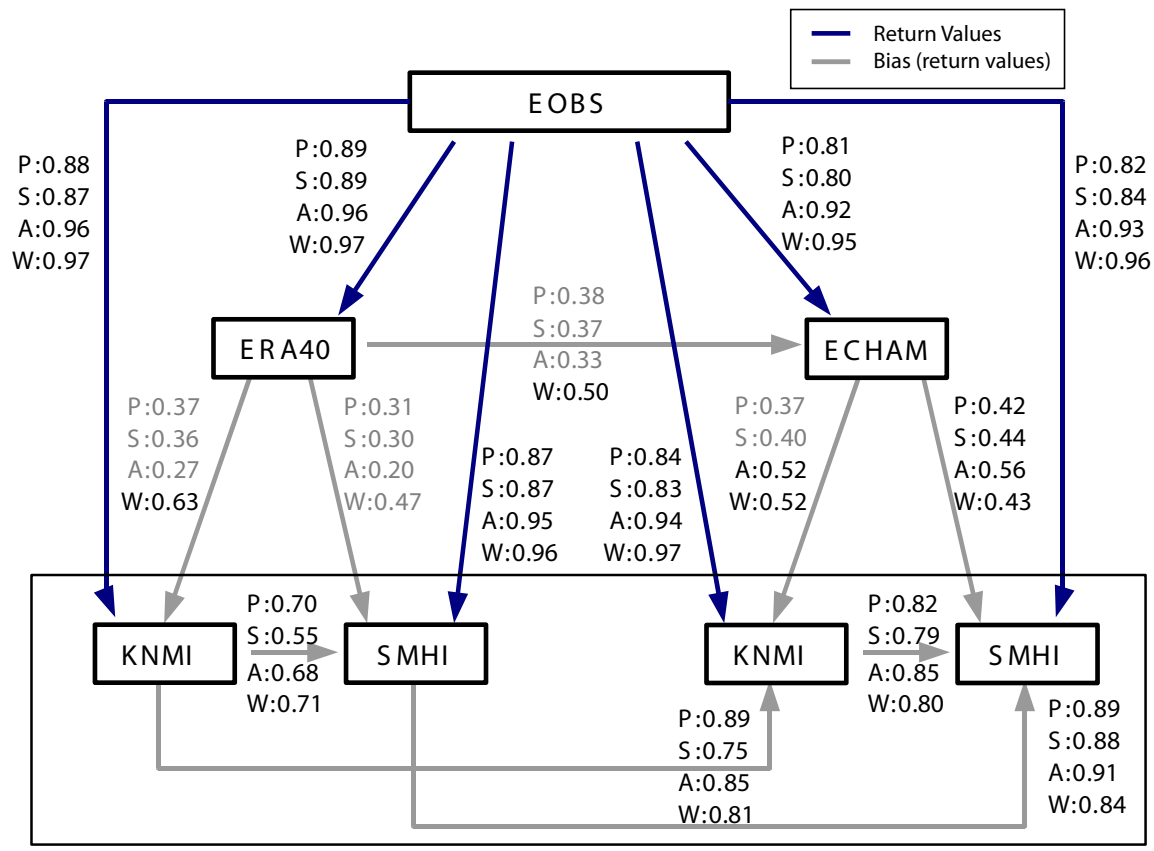

Fig. 7 Pearson's correlation among the maps of return period values for the observations (EOBS), the driving global models (ERA40 and ECHAM5) and regional models (KNMI and SMHI). Blue lines show correlations between the return period values, whereas gray lines indicate correlations between the anomalies (biases) w.r.t. observations E-OBS. Values significant at $95 \%$ confidence level are in black. In each case, correlations are computed for each particular season: Spring (P), Summer (S), Autumn (A) and Winter (W).

in Spring, not significant). By contrast, the high intra-RCM correlations obtained remark the ability of both RCMs to better represent the observed spatial pattern in comparison with the global forcings.

\subsection{Future changes in temperature extremes}

We analyze the future changes in temperature extremes considering the RCMs driven by the ECHAM5 A1B emission scenario for the period 2061-2100. Since robust bias patterns have been identified for the RCMs in present climate conditions, we shall apply the "delta method" to obtain the estimated return period values for future scenarios (see, e.g. Zahn and von Storch, 2010, and http://www.ipcc-data.org/ddc_change_field.html). This method consists of the comparison of simulated time slices of future scenarios relative to a simulated control scenario in the $20^{\text {th }}$ century (e.g. $20 \mathrm{c} 3 \mathrm{~m}$ scenario) of the same model. In the previous section, we analyzed the return period values obtained from the RCMs coupled to a control 20c3m scenario from ECHAM5 model. In this section, by contrast, we consider the RCM simulations driven by the future 2061-2100 time-slice output from ECHAM5 model for A1B scenario. Return levels corresponding to three return periods (20,40 and 100 years) have been estimated using the methodology described in Sec. 3. Figure 9 presents the differences of the 40-year re- 


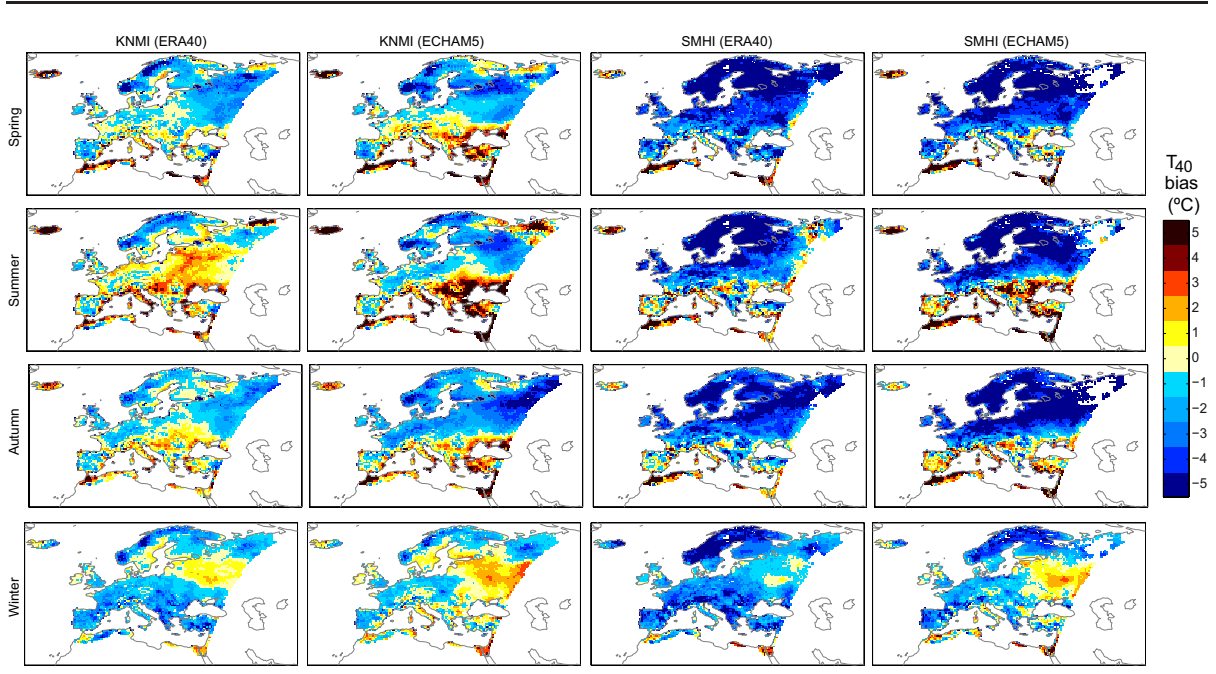

Fig. 8 Anomalies for the 40-year return period values from the KNMI/SMHI models with respect to the E-OBS dataset. The first two columns correspond to the KNMI model (ERA40 and ECHAM5-20c3m forcings, respectively) whereas the last two columns show the corresponding plots for SMHI.

turn period values for the future A1B (2061-2100) relative to 20c3m present climate (1961-2000) simulations for the KNMI and SMHI models. It is found that changes in extreme temperature, simulated by the two RCMs, have very similar patterns and presents increments almost everywhere. The greatest magnitudes of the warming occur over Southern Europe, except in winter, which shows the larger differences in the North-West of Europe. Other studies have also found the Southern Europe area more sensitive to climate change. For instance, the study by Nikulin et al (2011), presents an increase of temperature extremes in summer by the end of the century over all Europe, with higher increments in the South. The pattern of differences found in Figure 9 is almost the same for the other two return periods considered, with larger increment magnitudes for longer return periods (not shown).

\subsection{Comparison with changes in temperature means}

Finally, we compare the climate change response of extreme daily maximum temperatures described in the previous section with the response of the mean temperatures. Fig. 10 shows the seasonal mean values of the daily maximum temperature corresponding to the E-OBS dataset (see Fig. 5 for a comparison with 40-year return levels).

Figure 11 shows the climate change increments for the 40-year return levels in Fig. 9 , but expressed as a multiple of the mean temperature change during the same period (2061-2100 relative to 1961-2000), as simulated by the KNMI and SMHI models. This figure shows that extreme temperatures increase faster than the mean ones by a factor two, particularly during Spring and Summer in Southern and central Europe. Note that these results are in agreement with previous studies carried out using annual maxima (Sterl et al, 2008), and give further insight into the seasonality of these differences. 

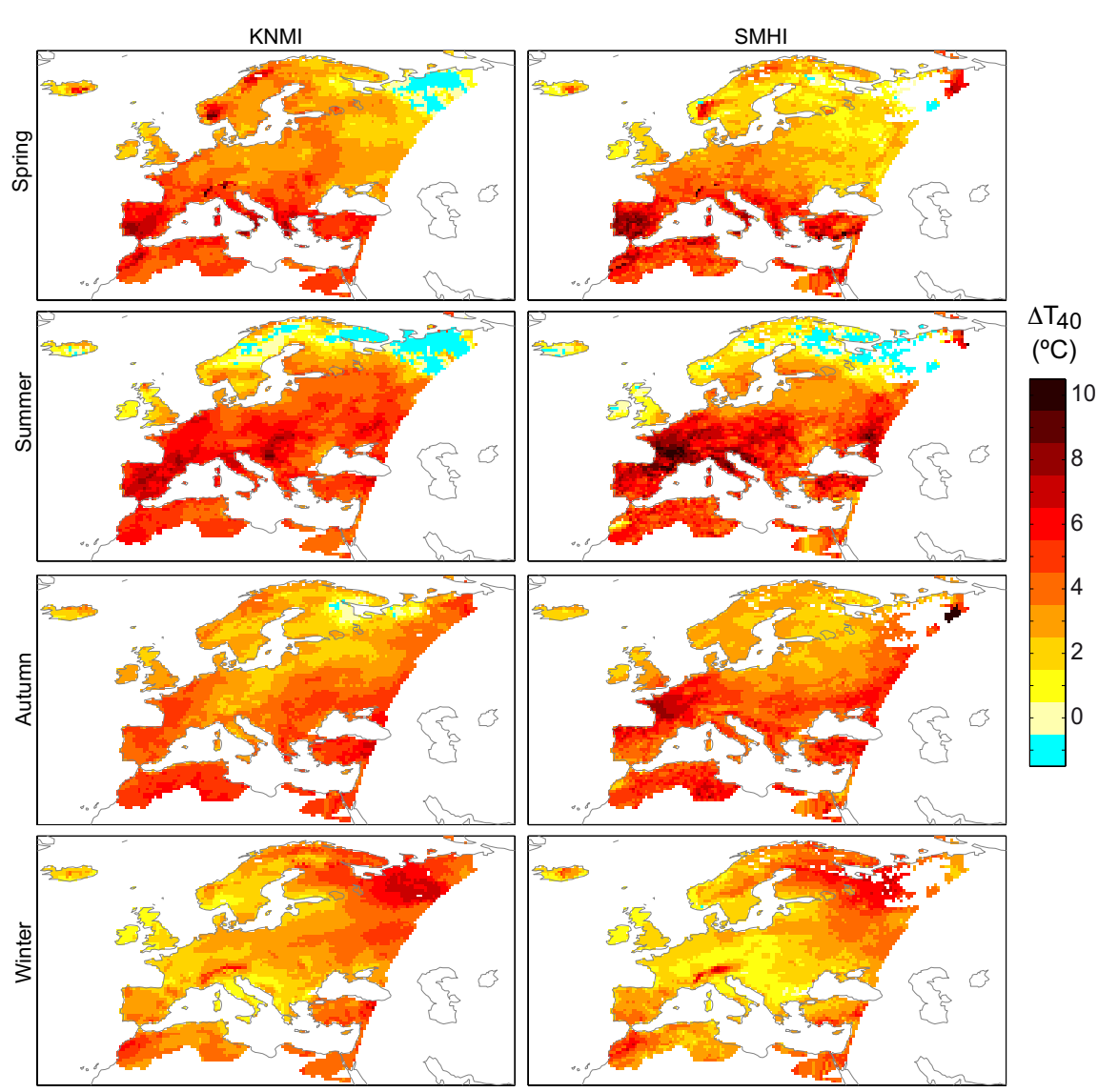

Fig. 9 Climate change increments for 40-year return levels $\left(\Delta T_{40}\right)$ in 2061-2100 relative to 1961-2000 simulated by the KNMI (left) and SMHI (right) RCMs, both driven by the ECMAH5 global model.
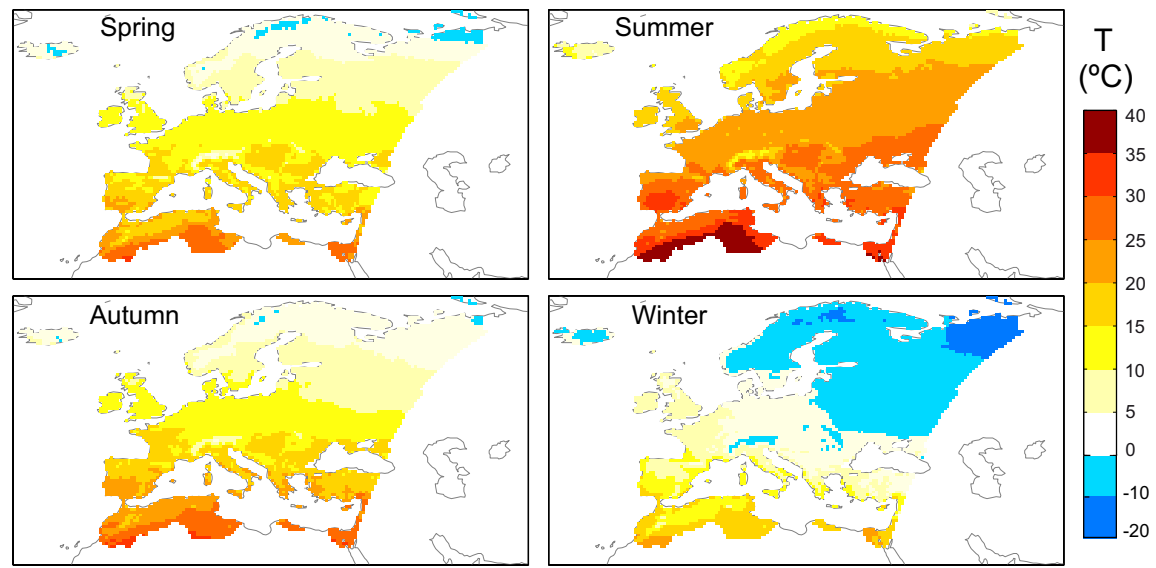

Fig. 10 Seasonal means for maximum daily temperatures $(T)$ from the E-OBS dataset. 


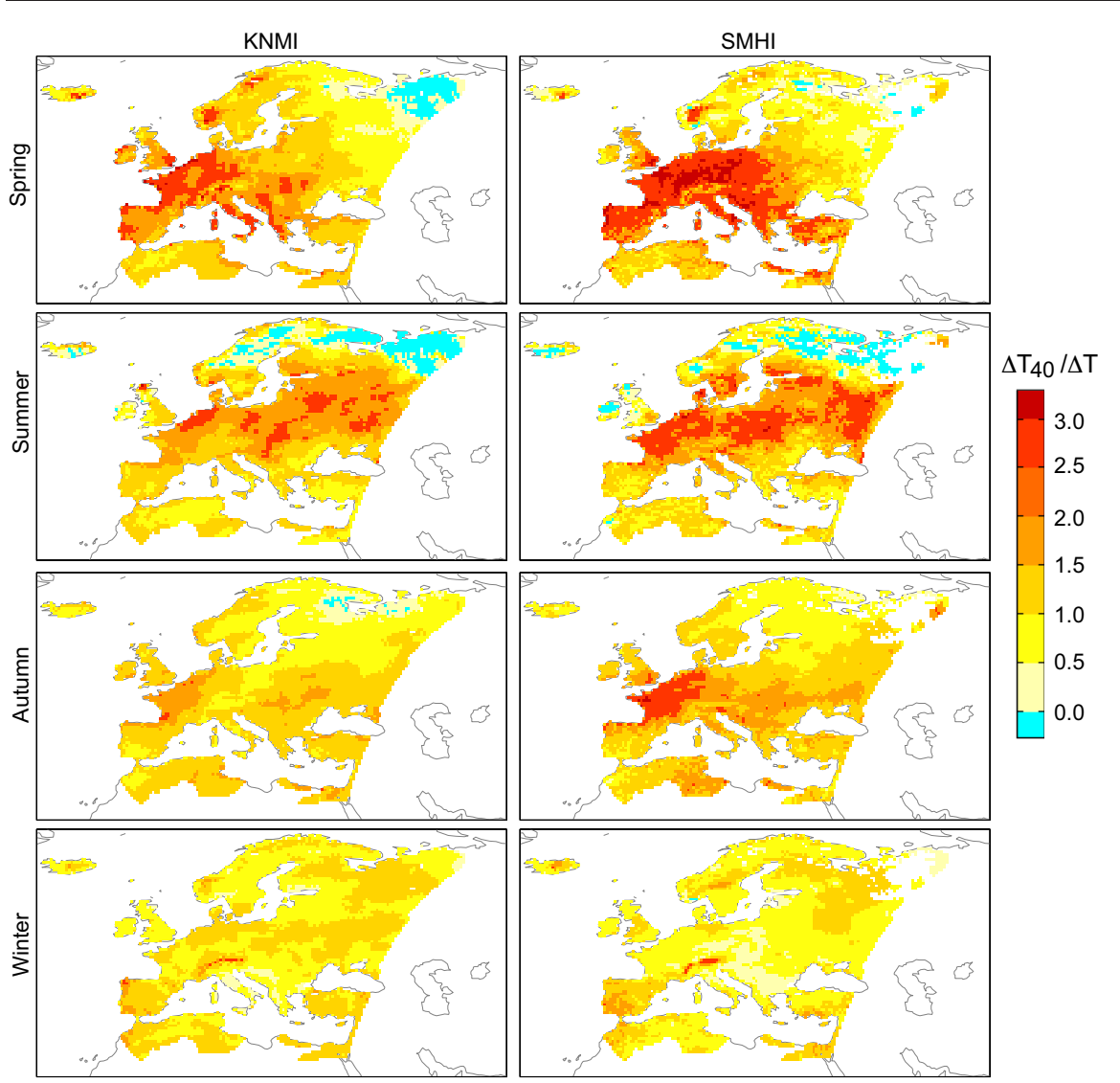

Fig. 11 Ratio between increments of 40-year return levels $\left(\Delta T_{40}: 2061-2100\right.$ relative to 1961 $2000)$ and increments of mean values ( $\Delta T: 2061-2100$ relative to 1961-2000) of daily maximum temperatures simulated by the KNMI (left) and SMHI (right) RCMs, both driven by the ECMAH5 global model.

\section{Conclusions}

Changes in extreme temperatures in Europe are examined in two state-of-the-art regional climate models (KNMI and SMHI) from the EU ENSEMBLES project. The performance of the regional models is analyzed against the high-resolution gridded E-OBS dataset, for the end of the 20th century (1961-2000), used as a calibration/validation period. Then, the projected changes for the period 2061-2100 considering the A1B emission scenario are evaluated.

Extremes are studied in terms of return period values using a time-dependent generalized extreme value model for monthly maximum temperatures. The model is based on harmonic functions and describes the seasonal cycle of the location, scale and shape parameters. The robustness of the nonstationary model is compared to the traditional stationary approach, revealing the consistency and coherency of the model proposed. This comparison also highlights the main advantage of this methodology, since there is no need to treat data and model fitting for each period separately, reducing the uncertainty in the estimation of seasonal and annual return period values. 
The time-dependent model is first applied to compare simulations from the RCMs to the observed natural variability reflected by the E-OBS dataset. Return period values for observed extreme temperatures (1961-2000), reveal a South-North gradient with larger values over the Mediterranean basin. Same pattern is found for the KNMI and SMHI simulations driven by both ERA-40 reanalysis and ECHAM5 20c3m scenario as boundary conditions. The bias estimation with respect to the E-OBS dataset reveals that the inter-RCM changes on the bias patterns are larger than the bias resulting from a change in the boundary conditions from ERA-40 to ECHAM5 20c3m scenario.

The response to increased green house gases, as projected by the A1B scenario, is consistent for both RCMs. The projected future changes of temperature extremes in 2061-2100, relative to the control period, reveals increments almost everywhere, showing the greatest magnitudes of warming over Southern Europe. This result agrees with other studies that have also detected this region to be more sensitive to a global warming (Giorgi and Lionello, 2008; Nikulin et al, 2011). It is remarkable that model projections for the 21st century shows greater temperature extremes than the increase of temperature found for the E-OBS data due to an increase of the return period.

The relative increment of temperature extremes projected for the future is also compared with respect to the changes of seasonal mean daily maximum temperatures for the same period. It is expected that the increments related to extremes will be larger than those associated with the mean seasonal temperatures, being two times higher in most of the European territory, particularly during Spring and Summer.

\section{A Aggregated quantile expression derivation}

This appendix explains in detail the derivation of the aggregated quantile expression (3). We use the analogy with the monthly stationary approach, which consist of the fitting of 12 GEV models, one for each month, using the maximum data associated with each month. Using these models, it is possible to calculate the probability of obtaining a maximum temperature value lower or equal to $\bar{x}_{q}$ during each month, i.e.:

$$
q_{i}=\exp \left\{-f_{i}\left(\bar{x}_{q}\right)\right\}
$$

where $f_{i}\left(\bar{x}_{q}\right)=\left[1+\xi_{i}\left(\frac{\bar{x}_{q}-\mu_{i}}{\psi_{i}}\right)\right]^{-1 / \xi_{i}}$. Note that location, scale and shape parameters are constant for each month. This expression allows obtaining the probability $q_{i}$, which corresponds to an annual probability, since each month occurs once a year.

The equivalent expression to (9) for the non-stationary approach is:

$$
q_{i}=\exp \left\{-\frac{\int_{(i-1) / 12}^{i / 12} f\left(\bar{x}_{q}, t\right) d t}{1 / 12}\right\}=\exp \left\{-12 \int_{(i-1) / 12}^{i / 12} f\left(\bar{x}_{q}, t\right) d t\right\},
$$

where the exponent corresponds to an average value of the function $f\left(\bar{x}_{q}, t\right)$ over the integration interval, for this reason, it is divided by the integration interval length. Note that expression (10) is the same as (3).

If using monthly maxima and the stationary approach, we want to calculate the annual maxima cumulative distribution function, the following expression is used:

$$
q=\prod_{i=1}^{12} q_{i}=\prod_{i=1}^{12} \exp \left\{-f_{i}\left(\bar{x}_{q}\right)\right\}=\exp \left\{-\sum_{i=1}^{12} f_{i}\left(\bar{x}_{q}\right)\right\} .
$$


For the non-stationary approach, and considering the relationship between (9) and (10), it becomes:

$$
\begin{aligned}
q & =\prod_{i=1}^{12} q_{i} \\
& =\prod_{i=1}^{12} \exp \left\{-12 \int_{(i-1) / 12}^{i / 12} f\left(\bar{x}_{q}, t\right) d t\right\} \\
& =\exp \left\{-\sum_{i=1}^{12} 12 \int_{(i-1) / 12}^{i / 12} f\left(\bar{x}_{q}, t\right) d t\right\} \\
& =\exp \left\{-12 \int_{0}^{1} f\left(\bar{x}_{q}, t\right) d t\right\},
\end{aligned}
$$

which is also the same as (3) but modifying the integration interval.

Acknowledgements The ENSEMBLES data used in this work was funded by the EU FP6 Integrated Project ENSEMBLES (Contract number 505539) whose support is gratefully acknowledged. We acknowledge the E-OBS data set and the data providers in the ECA\&D project (http://eca.knmi.nl). R. Mínguez is indebted to the Spanish Ministry MICINN for the funding provided within the "Ramon y Cajal" program. This work was partly funded by projects "GRACCIE" (CSD2007-00067, Programa Consolider-Ingenio 2010), "AMVAR" (CTM2010-15009) and EXTREMBLES (CGL2010-21869) from Spanish Ministry MICINN, by project C3E (200800050084091) and ESCENA (200800050084265) from the Spanish Ministry MARM, and by project MARUCA (E17/08) from the Spanish Ministry MF. The authors would like to especially thank the anonymous reviewers who helped to considerably improve the former versions of our manuscript.

\section{References}

Bretherton CS, Widmann M, Dymnikov VP, Wallace JM, Bladé I (1999) The effective number of spatial degrees of freedom of a time-varying field. J Climate 12:1990-2009

Brown SJ, Caesar J, Ferro CA (2008) Global changes in extreme daily temperature since 1950. J Geophys Res 113:D05,115

Christensen J, Hewitson B, Busuioc A, A Chen XG, Held I, Jones R, Kolli R, Kwon WT, Laprise R, Rueda VM, Mearns L, Menndez C, Risnen J, Rinke A, Sarr A, Whetton P (2007) Regional climate projections. In: Solomon S, Qin D, Manning M, Chen Z, Marquis M, Averyt K, Tignor M, Miller H (eds) Climate Change 2007: The Physical Science Basis. Contribution of Working Group I to the Fourth Assessment Report of the Intergovernmental Panel on Climate Change, Cambridge University Press, Cambridge

Coles S (2001) An Introduction to statistical modeling of extremes values. Springer, London

Cooley D (2009) Extreme value analysis and the study of climate change. a conebtart ib Wigley 1988. 97:77-83

Fischer E, Schar C (2010) Consistent geographical patterns of changes in high-impact european heatwaves. Nature Geoscience 3:398-403

Giorgi F, Lionello P (2008) Climate change projections for the mediterranean region. GLOBAL AND PLANETARY CHANGE 63(2-3, Sp. Iss. SI):90-104, DOI 10.1016/j.gloplacha.2007.09.005

Goubanova K, Li L (2007) Extremes in temperature and precipitation around the Mediterranean basin in an ensemble of future climate simulations. Global Planet Change 57:27-42

Haylock M, Hofstra N, Klein-Tank A, Klok EJ, Jones P, New M (2008) A European daily high-resolution gridded data set of surface temperature and precipitation for 1950-2006. J Geophys Res 113:D20,119 
Herrera S, Fita L, Fernández J, Gutiérrez JM (2010) Evaluation of the mean and extreme precipitation regimes from the ensembles regional climate multimodel simulations over spain. J Geophys Res 115:D21,117, DOI 10.1029/2010JD013936

Hofstra N, New M, McSweeney C (2010) The influence of interpolation and station network density on the distributions and trends of climate variables in gridded daily data. Climate Dynamics 35(5):841-858, DOI doi.10.1007/s00382-009-0698-1

Izaguirre C, Méndez FJ, Menéndez M, Luceño A, , Losada IJ (2010) Extreme wave climate variability in southern europe using satellite data. Journal of Geophysical Research 115(-):-, DOI doi:10.1029/2009JC005802, to appear

Kharin VV, Zwiers FW (2005) Estimating extremes in transient climate change simulations. J Climate 18:1156-1173

Kharin VV, Zwiers FW, Zhang XB (2005) Intercomparison of near-surface temperature and precipitation extremes in AMIP-2 simulations, reanalyses and observations. J Climate 18:5201-5223

Kioutsioukis I, Melas D, Zerefos C (2010) Statistical assessment of changes in climate extremes over Greece (1955-2002). Int J Climatol 30:1723-1737

Kjellstrom E, Giorgi F (2010) Introduction. Climate Research 44:117-119

Kunkel KE, Andsager K, Easterling DR (1999) Long-term trends in extreme precipitation events over the conterminous United States and Canada. J Climate 12:2515-2527

van der Linden P, Mitchell J (eds) (2009) ENSEMBLES: Climate Change and its Impacts: Summary of research and results from the ENSEMBLES project. Met Office Hadley Centre, FitzRoy Road, Exeter EX1 3PB, UK

Meehl GA, Covey C, Delworth T, Latif M, McAvaney B, Mitchell JFB, Stouffer RJ, Taylor KE (2007) The wcrp cmip3 multi-model dataset: A new era in climate change research. Bull Amer Meteor Soc 88:1383-1394

Méndez FJ, Menéndez M, Luceño A, Losada IJ (2007) Analyzing monthly extreme sea levels with a time-dependent gev model. J Atmos Ocean Technol 24:894-911

Menéndez M, Méndez FJ, Izaguirre C, no AL, Losada I (2009) The influence of seasonality on estimating return values of signifcant wave height. Coastal Engineering 56:211-219

Mínguez R, Méndez FJ, Izaguirre C, Menéndez M, Losada IJ (2010a) Pseudo-optimal parameter selection of non-stationary generalized extreme value models for environmental variables. Environmental Modelling \& Software 25:1592-1607, DOI DOI: 10.1016/j.envsoft.2010.05.008

Mínguez R, Menéndez M, Méndez FJ, Losada IJ (2010b) Sensitivity analysis of time-dependent generalized extreme value models for ocean climate variables. Advances in Water Resources 33:833-845, 10.1016/j.advwatres.2010.05.003

Morton ID, Bowers J, Mould G (1997) Estimating return period wave heights and wind speeds using a seasonal point process model. Coastal Engineering 31:305-326

Nikulin G, Kjellstrom E, Hansson U, Strandberg G, Ullerstig A (2011) Evaluation and future projections of temperature, precipitation and wind extremes over Europe in an ensemble of regional climate simulations. TELLUS SERIES A-DYNAMIC METEOROLOGY AND OCEANOGRAPHY 63(1):41-55, DOI 10.1111/j.1600-0870.2010.00466.x

Rust H, Maraun D, Osborn T (2009) Modelling seasonality in extreme precipitation. Eur Phys J 174:99-111

Shär C, Jendrithzky G (2004) The European heat wave of 2003: Was it merely a rare meteorological event or a first glimpse of climate change to come? probably both, is the answer, and the anthropogenic contribution can be quantified. Nature 432:559-560

Sterl A, Severijns C, Dijkstra H, Hazeleger W, van Oldenborgh GJ, van den Broeke M, Burgers G, van den Hurk B, van Leeuwen PJ, van Velthoven P (2008) When can we expect extremely high surface temperatures? Geophysical Research Letters 35:L14,703+, DOI 10.1029/2008GL034071, URL http://dx.doi.org/10.1029/2008GL034071

Tebaldi C, Hayhoe K, Arblaster JM, Meehl GA (2006) Going to the extremes: an intercomparison of model simulated historical and future changes in extreme events. Climate Change 3-4:185-211

Uppala SM, et al (2005) The ERA-40 re-analysis. Quart J Roy Meteor Soc 131:2961-3012

Zahn M, von Storch H (2010) Decreased frequency of North Atlantic polar lows associated with future climate warming. Nature 467:309-312 